\title{
CYP1A2 rs762551 polymorphism contributes to cancer susceptibility: a meta-analysis from 19 case-control studies
}

\author{
Hongge Wang ${ }^{1}$, Zhi Zhang ${ }^{2}$, Sugui Han ${ }^{3}$, Yujuan Lu², Fumin Feng ${ }^{1}$ and Juxiang Yuan ${ }^{1 *}$
}

\begin{abstract}
Background: Genetic polymorphism (rs762551A>C) in gene encoding cytochrome P450 1A2 (CYP1A2) has been shown to influence the inducibility of CYP1A2 expression and thus might be associated with risk of several types of human cancer. However, the results of previous studies on the associations of this polymorphism with risk of cancer are not all consistent. To clarify the potential contribution of CYP1A2 rs762551 to cancer risk, we performed a meta-analysis of the published case-control studies.

Methods: We used PubMed, Embase, OVID, ScienceDirect, and Chinese National Knowledge Infrastructure databases to identify the related publications for this meta-analysis. The pooled odds ratio (OR) and 95\% confidence interval (Cl) were calculated using random effect model to evaluate the association of rs762551 with cancer risk. A $x^{2}$-based Q-test was used to examine the heterogeneity assumption and the funnel plot and Egger's test were used to examine the potential publication bias. The leave-one-out sensitivity analysis was conducted to determine whether our assumptions or decisions have a major effect on the results of the review.
\end{abstract}

Results: Our analysis of 19 eligible case-control studies showed a significant association between rs762551C variant with risk of cancer in the genetic model of $C C$ versus $A A(O R=1.30,95 \% \mathrm{Cl}=1.02-1.64)$ and the dominant model $(\mathrm{OR}=1.19,95 \% \mathrm{Cl}=1.04-1.36)$. In subgroup analysis based on ethnicity, the rs762551CC genotype was associated with increased cancer risk $(\mathrm{OR}=1.29,95 \% \mathrm{Cl}=1.27-1.63$ in co-dominate model and $\mathrm{OR}=1.17,95 \% \mathrm{Cl}=1.02-1.34$ in dominant model in Caucasians, but not in Asians and the mixed population.

Conclusion: These results suggested that CYP1A2 rs762551 polymorphism is likely to be associated with susceptibility to cancer in Caucasians.

Keywords: CYP1A2, Cancer, Meta-analysis, Polymorphism

\section{Background}

The cytochromes P450 (CYPs) played an important role in the development of various cancers, since they involved in the metabolic transformation of numerous endogenous and exogenous compounds including carcinogens and anti-cancer drugs [1]. Cytochrome P450 1A2 (CYP1A2), as one of important CYP enzymes, is responsible for the metabolic activation of pro-carcinogens such as heterocyclic aromatic amines (HAA), polycyclic aromatic hydrocarbons (PAHs) and 4-methylnitrosamino-1-(3-

\footnotetext{
*Correspondence: yuanjx@heuu.edu.cn

${ }^{1}$ Department of Epidemiology, College of Public Health, Hebei United University, Tangshan 063000, China

Full list of author information is available at the end of the article
}

pyridyl)-1-butanone (NNK) and further contributes to the risk of cancer $[2,3]$.

CYP1A2 gene has been mapped on chromosome $15 \mathrm{q} 24.1$ and head to head shares a bidirectional promoter with CYP1A1 gene [4]. It has been demonstrated that the expression of CYP1A2 existed large interindividual variability in the liver [5] and it is believed that the expression of CYP1A2 is regulated by constitutive expression and inducible expression from environmental chemicals $[3,6]$.

CYP1A2 is highly polymorphic and there are more than 200 polymorphisms existed in CYP1A2 gene region according to NCBI dbSNP database (http://www.ncbi.nlm. nih.gov) and SNP500Cancer (http://variatgps.nci.nih.gov). 
Previous studies have extensively focused on CYP1A2 $-164 \mathrm{~A}>\mathrm{C}$ polymorphism (CYP1A2*1F; rs762551) [7,8], which is located in the intron 1 of $C Y P 1 A 2$. There also have several reported studied three common variations, that is $-3860 \mathrm{G}>\mathrm{A}$ polymorphism (CYP1A2*1C; rs2069514) $[8,9],-739 \mathrm{G}>\mathrm{T}$ polymorphism (rs2069526) [8,10] and $1545 \mathrm{~T}>\mathrm{C}$ polymorphism (rs2470890) $[10,11]$. These polymorphisms may be related to altered inducibility of CYP1A2 expression by environmental chemicals and consequently influence the individual susceptibility to certain cancer. For example, the CYP1A2 rs2069514 A allele has been demonstrated to associated with decreased enzyme activity in smokers and CYP1A2 rs762551 polymorphism is also associated with altered expression of CYP1A2 by cigarette smoking [12-14].

Recently, many studies have investigated the association of CYP1A2 polymorphisms and the risk of various cancers, including lung cancer, breast cancer, colorectal cancer, stomach cancer and others in various populations [15-18]. However, the results of these studies are not consistent and inconclusive. Considering the role of CYP1A2 in defending against environmental carcinogens and in the development of cancers, we performed a systematic meta-analysis from all eligible studies to address the overall risk of CYP1A2 variants in the development of all cancers involved.

\section{Methods}

\section{Identification and eligibility of relevant studies}

Remote PubMed, Embase, OVID, ScienceDirect, and Chinese National Knowledge Infrastructure database (between January 2003 and December 2011) was searched using the search terms: CYP1A2/P4501A2/phase II enzymes, polymorphism/polymorphisms/genotype and cancer/ carcinoma/adenomas to identify all publications, which investigated the association of the CYP1A2 polymorphism with cancer risk in all ethnic populations. We evaluated the titles and abstracts of all relevant papers, but excluded case reports, editorials and reviews. All publications in English language with available full text matching the eligible criteria were retrieved. For inclusion in this metaanalysis, the identified articles had to provide information on the following: (1) using a case-control design, (2) sufficient data for examining an odds ratio (OR) with 95\% confidence interval (CI) and (3) was a study of the CYP1A2 rs762551 polymorphism and cancer risk, (4) genotype distributions of polymorphism are consistent with hardyWeinberg Equilibrium (HWE). In addition, we checked the references of relevant reviews and eligible articles that our search retrieved by two investigators independently.

\section{Methods for quantitative analysis}

We examined the association between CYP1A2 rs762551 $\mathrm{A}>\mathrm{C}$ polymorphism and the risk of cancer by calculating pooled odds ratio (ORs) and 95\% confidence intervals (CI) in genetic model of $\mathrm{CC}$ versus $\mathrm{AA}$, dominant model $(\mathrm{CC}+\mathrm{CA}$ versus $\mathrm{AA})$ and recessive model $(\mathrm{CC}$ versus $\mathrm{CA}+\mathrm{AA})$. The significance of pooled $\mathrm{OR}$ was tested by $\mathrm{Z}$ test. The $\chi 2$-based Q-test was also used to examine the heterogeneity assumption [19]. If studies' findings only differ by the sampling $(P \geq 0.05)$, a fixed-effects model could be used to calculate the combined OR. By contrast, if the $P$ value of the $Q$ tests is below 0.05 , which showed that the study results statistically differ by heterogeneous case and sampling, a random-effects model could be more suitable. Since we used accumulating data from a series of studies, which had been conducted by researchers operating independently, the random model was more easily justified than the fixed model [20,21]. The summary OR and $95 \%$ CI were calculated under the random effect model.

The leave-one-out sensitivity analysis was conducted to determine whether our assumptions or decisions have a major effect on the results of the review by omitting each study (one at a time) [22]. Furthermore, subgroup analyses were performed to test whether the effect size varied by the ethnicity and the source of control population. To evaluate the published bias, we used funnel plot analysis, which is graphical display of sample size plotted against effect size for the studies included in a metaanalysis [23]. To test for funnel plot asymmetry, Egger's test was performed [24]. All of calculations were performed using $\mathrm{R}$ program.

\section{Results}

\section{Characteristics of meta-analyses database}

After preliminary screening as of 15 December 2011, there were 53 relevant publications fitting the key terms. We excluded 34 studies by (1) no related CYP1A2 polymorphism, (2) no cancer case-control design, (3) review articles [25,26], (4) no usable genotype data [27-30] and included 19 studies [7-11,16-18,31-41] in this metaanalysis (Figure 1 and Table 1). Overall, the studies involved in 8,218 cases and 11,165 controls. The genotype distributions for CYP1A2 rs762551 polymorphism are shown in Table 2.

The characteristics of populations and cancer types of final 19 publications were listed in Table 1. This metaanalysis involved in 5 breast cancer studies, 5 lung cancer studies, 4 colorectal cancer studies and 5 studies with other cancer types. Of these, there were 10 studies conducted in Caucasian, 7 studies in Asian, 1 study in Tunisian, and 1 study included multiple ethnicities. There were 6 population-based studies, 12 hospital-based studies, and 1 study with mixed controls study. Variant genotyping methods were used, which included polymerase chain reaction restriction fragment length polymorphism assay (PCR-RFLP) in 14 studies, TaqMan assay, MassARRAY, 


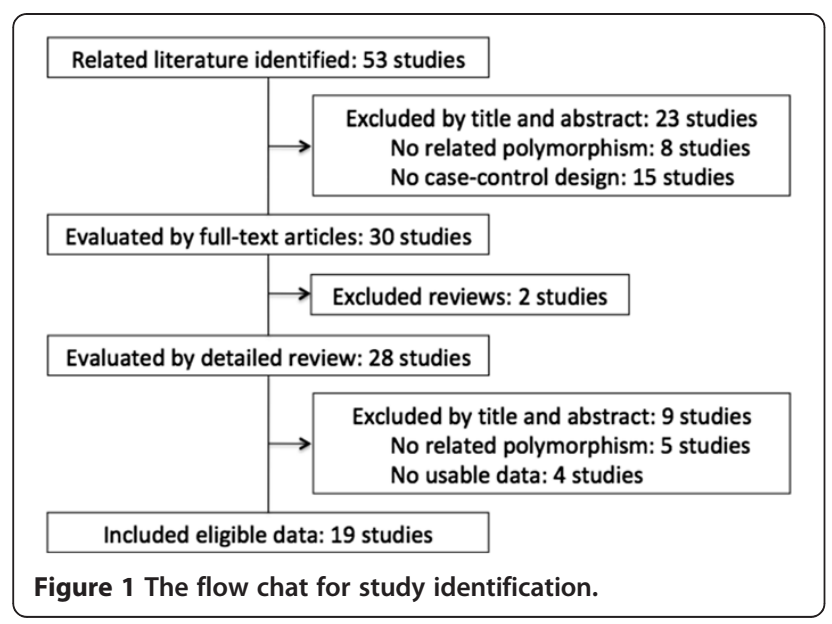

microarray, arrayed primer extension (APEX) and unknown method in one study each. Overall, the genotyping frequencies of CYP1A2 rs762551 polymorphism were in agreement with the Hardy-Weinberg equilibrium in both cases and controls.

\section{Quantitative synthesis}

Regarding CYP1A2 rs762551 polymorphism, the eligible studies involved in 8218 cases and 11165 controls. For each study, we investigated the association based on the assumption of different inheritance models of CYP1A2 rs762551 A>C polymorphism. In all inheritance models of rs762551 polymorphism, due to the between-study heterogeneity in the individual studies (all $P$ for $\mathrm{Q}$ test $<0.01$ and $\mathrm{I}^{2}>25 \%$ ), the random-effect model was used to analyze the data [42]. We identified that rs762551 polymorphism had a weak correlation with the risk of cancer $(\mathrm{CC}$ versus $\mathrm{AA}, \mathrm{OR}=1.30,95 \% \mathrm{CI}=1.02-1.64$; dominant model, $\mathrm{OR}=1.19,95 \% \mathrm{CI}=1.04-1.36)$, but not in recessive model $(\mathrm{OR}=1.19,95 \% \mathrm{CI}=0.99-1.44)$ (Figure 2 and Table 2).

Several subgroup analyses were also performed according to the population ethnicity, cancer type, or source of control population (Table 2). When we analyzed the relationship of rs762551 polymorphism and cancer risk in different ethnicity subgroup. Our data showed that rs762551 $\mathrm{A}>\mathrm{C}$ polymorphism increased the cancer risk $(\mathrm{CC}$ versus $\mathrm{AA}, \mathrm{OR}=1.29,95 \% \mathrm{CI}=1.27$ 1.63; dominant model, $\mathrm{OR}=1.17,95 \% \mathrm{CI}=1.02-1.34)$ in Caucasians, but not in Asians (CC versus AA, OR = 1.27, $95 \% \mathrm{CI}=0.83-1.93$; dominant model, $\mathrm{OR}=1.24$, 95\% $\mathrm{CI}=0.93-1.66)$ and in other mixed population (CC versus $\mathrm{AA}, \mathrm{OR}=1.34,95 \% \mathrm{CI}=0.14-12.95$; dominant model, $\mathrm{OR}=0.87,95 \% \mathrm{CI}=0.17-4.40)$. In recessive genetic model, our study didn't show any significant correlation between rs762551 polymorphism and the cancer risk with OR (95\% CI) of 1.19 (0.98-1.45), 1.10 (0.76-1.59) and 1.68 (0.44-6.35) in Caucasians, Asians and other

Table 1 Characteristics of the studies included in the meta-analysis

\begin{tabular}{|c|c|c|c|c|c|c|c|c|}
\hline Author & Year & Country & Ethnicity & Cancer type & Cases & Controls & Source of controls & Genotype method \\
\hline Khvostova [7] & 2011 & Russia & Caucasian & Breast & 323 & 526 & Hospital & PCR-RFLP \\
\hline MARIE-GENICA [31] & 2010 & German & Caucasian & Breast & 3147 & 5485 & Population & PCR-RFLP \\
\hline Singh [8] & 2010 & India & Asian & Lung & 200 & 200 & Population & PCR-RFLP \\
\hline Sangrajrang [16] & 2009 & Thailand & Asian & Breast & 552 & 483 & Hospital & TaqMan \\
\hline B/chir [9] & 2009 & Tunisia & Tunisian & Lung & 101 & 98 & Hospital & PCR-RFLP \\
\hline Kobayashi [17] & 2009 & Japan & Asian & Stomach & 141 & 286 & Hospital & MassARRAY \\
\hline Altayli [32] & 2009 & Turkey & Caucasian & Bladder & 135 & 128 & Hospital & PCR-RFLP \\
\hline Aldrich [33] & 2009 & USA & Mixed & Lung & 113 & 299 & Mixed & Not defined \\
\hline Saebo [35] & 2008 & Norway & Caucasian & Colorectal & 198 & 222 & Hospital & PCR-RFLP \\
\hline Suziki [34] & 2008 & USA & Caucasian & Pancreatic & 649 & 585 & Population & PCR-RFLP \\
\hline Yoshida [36] & 2007 & Japan & Asian & Colorectal & 64 & 111 & Hospital & PCR-RFLP \\
\hline Osawa [18] & 2007 & Japan & Asian & Lung & 103 & 111 & Hospital & PCR-RFLP \\
\hline Gemignani [10] & 2007 & Italy & Caucasian & Lung & 297 & 310 & Hospital & Microarray \\
\hline Kotsopoulos [37] & 2007 & Canada & Caucasian & Breast & 170 & 241 & Hospital & PCR-RFLP \\
\hline Bae [40] & 2006 & Korea & Asian & Colorectal & 111 & 93 & Hospital & PCR-RFLP \\
\hline Long [38] & 2006 & China & Asian & Breast & 1082 & 1139 & Population & PCR-RFLP \\
\hline Li [39] & 2006 & USA & Caucasian & Pancreatic & 307 & 333 & Population & PCR-RFLP \\
\hline Landi [11] & 2005 & spain & Caucasian & Colorectal & 361 & 321 & Hospital & APEX \\
\hline Goodman [41] & 2003 & USA & Caucasian & Ovarian & 164 & 194 & Population & PCR-RFLP \\
\hline
\end{tabular}

$P C R$, polymerase chain reaction; $R F L P$, restriction fragment length polymorphis; $A P E X$, arrayed primer exension. 
Table 2 CYP1A2 rs762551 polymorphism and cancer risk stratified by characteristics of studies

\begin{tabular}{|c|c|c|c|c|c|c|c|}
\hline \multirow[t]{2}{*}{ Variables } & \multicolumn{4}{|c|}{ Genotype of rs762551 (Cases/Controls) } & \multirow{2}{*}{$\begin{array}{c}\text { CC vs AA } \\
\text { OR }(95 \% \mathrm{Cl})\end{array}$} & \multirow{2}{*}{$\begin{array}{c}\text { Dominant model } \\
\text { (CC+CA vs AA) } \\
\text { OR }(95 \% \mathrm{Cl})\end{array}$} & \multirow{2}{*}{$\begin{array}{c}\text { Recessive model } \\
\text { (CC vs CA+AA) } \\
\text { OR }(95 \% \mathrm{Cl})\end{array}$} \\
\hline & Total & AA & $A C$ & $\mathrm{CC}$ & & & \\
\hline All & $8218 / 11165$ & $3750 / 5374$ & $3567 / 4720$ & $901 / 1071$ & $1.30(1.02-1.64)^{*}$ & $1.19(1.04-1.36)^{*}$ & $1.19(0.99-1.44)$ \\
\hline \multicolumn{8}{|l|}{ Cancer site } \\
\hline Lung & $814 / 1018$ & $277 / 426$ & $380 / 443$ & $157 / 149$ & $1.27(0.63-2.61)$ & $1.09(0.63-1.89)$ & $1.27(0.82-1.95)$ \\
\hline Colorectal & $734 / 747$ & $288 / 366$ & $362 / 310$ & $84 / 71$ & $1.50(0.96-2.33)$ & $1.52(0.95-2.42)$ & $1.15(0.73-1.81)$ \\
\hline Breast & $5274 / 7874$ & $2544 / 3848$ & $2204 / 3331$ & $526 / 695$ & $1.44(0.82-2.55)$ & $1.07(0.93-1.24)$ & $1.15(0.73-1.81)$ \\
\hline Other & $1396 / 1526$ & $641 / 734$ & $621 / 636$ & $134 / 156$ & $1.04(0.79-1328)$ & $1.12(0.96-1.31)$ & $0.97(0.73-1.30)$ \\
\hline \multicolumn{8}{|l|}{ Ethnicity } \\
\hline Caucasian & $5751 / 8345$ & 2804/4199 & $2417 / 3463$ & $530 / 683$ & $1.29(1.27-1.63)^{*}$ & $1.17(1.02-1.34)^{*}$ & $1.19(0.98-1.45)$ \\
\hline Asian & $2253 / 2423$ & $867 / 989$ & $1055 / 1086$ & $331 / 348$ & $1.27(0.83-1.93)$ & $1.24(0.93-1.66)$ & $1.10(0.76-1.59)$ \\
\hline Mixed & 214/397 & 79/186 & $95 / 171$ & $40 / 40$ & $1.34(0.14-12.95)$ & $0.87(0.17-4.40)$ & $1.68(0.44-6.35)$ \\
\hline \multicolumn{8}{|c|}{ Source of Controls } \\
\hline Population & $5549 / 7936$ & $2590 / 3777$ & 2388/3387 & $571 / 772$ & $1.01(0.89-1.14)$ & $1.02(0.92-1.14)$ & $1.00(0.89-1.13)$ \\
\hline Hospital & $2556 / 2930$ & $1114 / 1426$ & $1128 / 1219$ & $314 / 285$ & $1.35(0.97-1.88)$ & $1.21(0.98-1.50)$ & $1.26(0.96-1.65)$ \\
\hline Other & 113/299 & $46 / 171$ & $51 / 114$ & $16 / 14$ & $4.25(1.93-9.34)^{*}$ & $1.95(1.25-3.02)^{*}$ & $3.36(1.58-7.13)^{*}$ \\
\hline
\end{tabular}

${ }^{*} P<0.05$.

mixed population, respectively (Figure 2 and Table 2). We didn't observe any significant association among other subgroups (cancer type and source of control) subgroup in any genetic model using random effect model (Table 2).

\section{Sensitivity analysis}

In order to compare the sensitivity of the meta-analysis, we conducted a leave-one-out sensitivity analysis (Additional file 1: Table S1). A single study involved in this meta-analysis was evaluated each time to reflect the influence of the individual data set to pooled ORs. The results pattern was not impacted by single study in all genetic models. The $P$ for $\mathrm{Q}$ test and the $\mathrm{I}^{2}$ value also showed that none of single study affected the heterogeneity of this meta-analysis.

\section{Statistical uncertainty of finding}

For risk assessment, statistical uncertainty is associated with the model selected [43]. In this meta-analysis, we evaluated the association of CYP1A2 rs762551 polymorphism with cancer risk in different genetic models (CC versus AA model, dominant model and recessive model). The results showed the difference among these genetic models. We found the rs672551 polymorphism was associated with cancer risk under $\mathrm{CC}$ versus AA model and dominant model, but not under recessive model.

\section{Bias diagnostics}

To evaluate the publication bias of rs762551 variant in the overall meta-analysis, the funnel plot and Egger's test were used. In this analysis, the funnel plot showed a relatively symmetric distribution (Figure 3 ), but the point cloud didn't have a distinctive form. No publication bias was detected by the Egger's test $(t=1.4870, P=0.1553)$. However, the deficient funnel form of the funnel plot could be due to the relatively high heterogeneity with respect to the different ethnicity and the source of control population. Furthermore, the number of studies was relatively small and the publication bias may still exist.

\section{Discussion}

Various studies provided evidences that genetics play an important role in determining cancer risk and association studies have been identified to evaluate cancer susceptibility [44]. However, many association studies failed to provide convincing evidence of linkage and have resulted in contradicting findings, especially in small sample sizes [45]. Meta-analysis provided a popular method for combining world literatures across studies to resolve the statistical power and discrepancy problem in associate studies [46]. Based on 19 studies providing data on CYP1A2 rs762551 polymorphism and cancer risk, we conduced a meta-analysis involving in 8218 cancer cases and 11165 controls to indicate if the rs762551 polymorphism was significantly associated with risk of cancer. We evaluated the publication bias. The CYP1A2 rs762551 A>C genotypes funnel plot was approximately symmetrical and the Eggle's test showed that there is no publication bias in the study of CYP1A2 rs762551 ( $P=$ 0.1553). We found that the carriers of CYP1A2 rs762551 $\mathrm{C}$ allele had a weak effect on the overall cancer risk in 


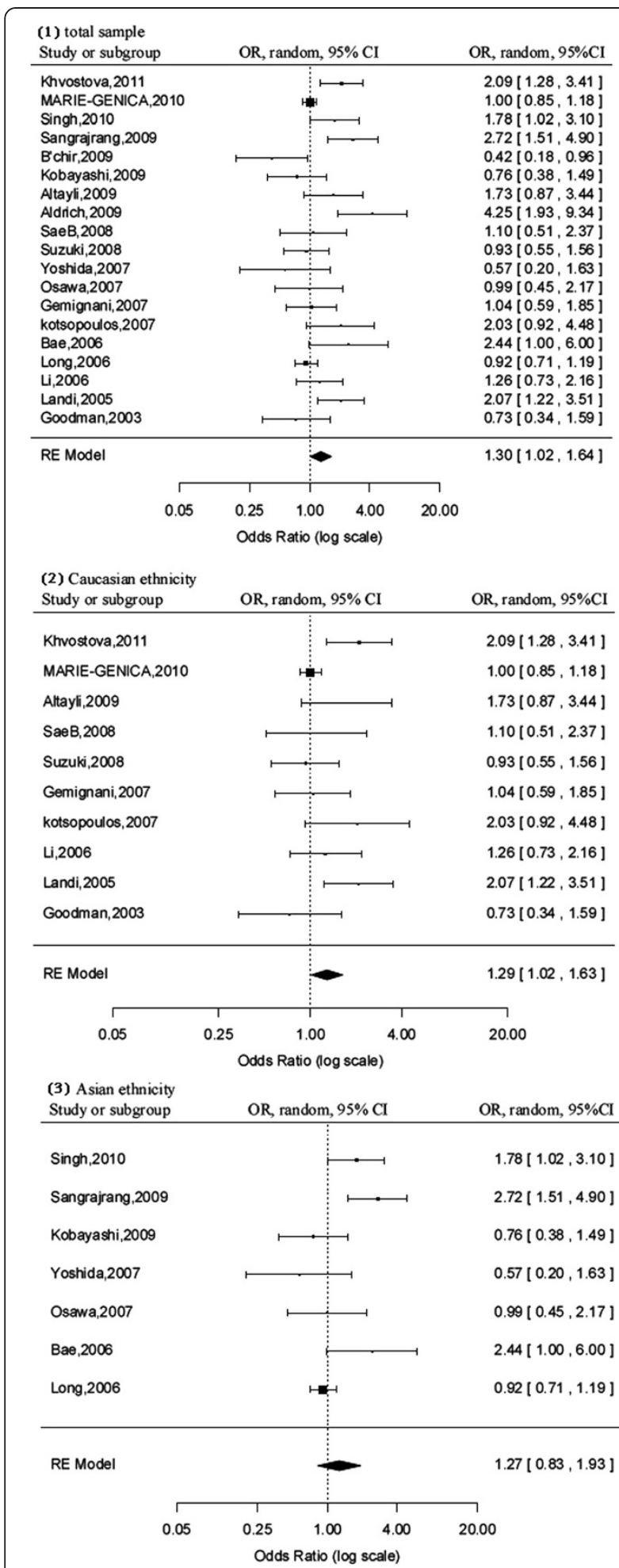

Figure 2 Forest plot of cancer risk associated with CYP1A2 rs762551 polymorphism in different ethnicity. Pooled odds ratio (OR) for (1) total samples, (2) Caucasians ethnicity, and (3) Asians ethnicity. The genetic models are CC versus AA. The squares and horizontal lines correspond to the study-specific odds ratio (OR) and 95\% confidence interval (Cl).

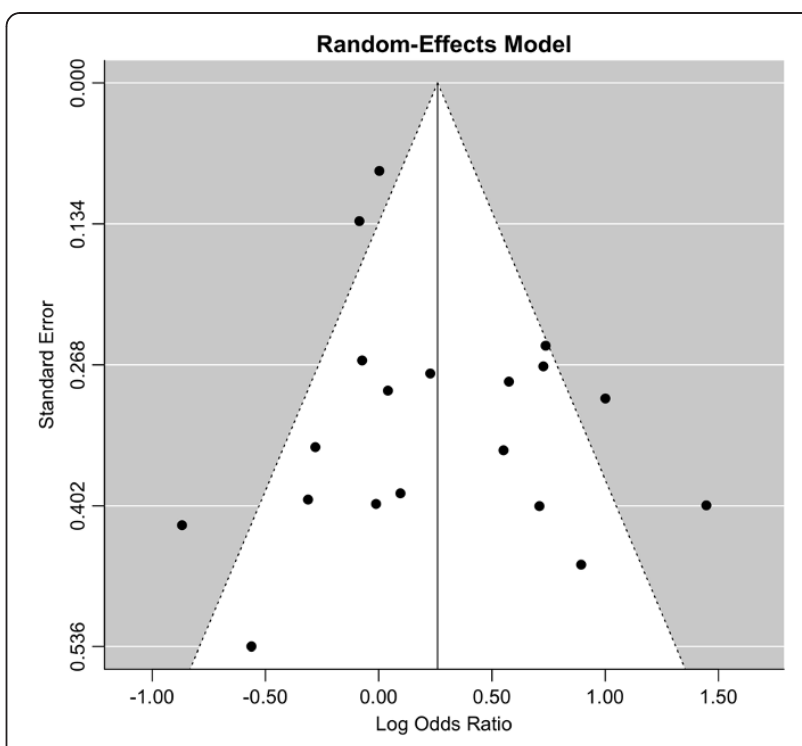

Figure 3 Funnel plot analysis to detect publication bias for rs762551 polymorphism (CC versus AA). Each point represents an individual study for the indicated association.

allele genetic model and in the dominant genetic model. These results suggested that the CYP1A2 rs762551 polymorphism might be useful for assessing cancer risk.

CYP1A2 is a critical enzyme involved in drug metabolism and carcinogen bioactivation. The expression and activity of CYP1A2 has been demonstrated to relate to the risk of various cancers $[2,6,41,47]$. CYP1A2 gene is genetically polymorphic in human. To date, 177 SNPs have been deposited in the NCBI database and the frequency of these SNPs varies by ethnicity. Many of these SNPs are in linkage disequilibrium and a few SNPs have been reported to be functional [14,48]. For example, CYP1A2*1F (rs762551) polymorphism can result in 2-3 fold increase in activity/protein and has been associated with inducibility [49]. Our current analysis showed that the CC genotype of rs762551 elevated the individual susceptibility to the cancer risk. This is consistent to the function of CYP1A2 rs762551 polymorphism. However, we didn't observe any correction of CC genotype with the cancer risk in subgroup analysis by cancer type. This biochemical mechanism was still unclear. In addition, due to the low OR in our study, our results should be interpreted cautiously. The CYP1A2 polymorphism may prove to be useful for assessing cancer risk.

It has been well known that cancer occurrence and mortality varied by ethnicity and geographic location [50]. In this meta-analysis, all subjects were subgrouped into three groups (Caucasian, Asian and other populations). No association of rs762551 polymorphism with cancer risk was detected in Asian and mixed population, while increased cancer risk was demonstrated in Caucasians. This finding reflected the difference of cancer susceptibility 
in different ethnicity, due to different genetic background and environmental exposure. However due to the low OR in this meta-analysis, further investigation still need to be conducted in a large scale Asian population.

Any meta-analysis has it limitations. To better interpreting the finding, several limitations need to be considered in current analysis. Firstly, potential publication biases may exist in this meta-analysis because studies excluded the non-English-language publications. Secondly, the total study size was still too small to perform subgroup analysis. Thirdly, this meta-analysis was based on unadjusted data due to a lack of detailed genotype information stratified by main confounding variables, such as gender, age, smoking status in original articles.

\section{Conclusions}

In summary, our meta-analysis demonstrated a weak association of CYP1A2 rs762551 polymorphism with cancer risk, mainly in Caucasian population. However, as a potentially powerful tool for assessing population effects of genetic variants, meta-analysis cannot replace for adequate genetic association studies. Also, to reach a more definitive conclusion, further gene-gene interaction and gene-environment interaction studies, which based on large sample size, are still needed in different population.

\section{Additional file}

Additional file 1: Table S1. ORs (95\% Cl) of sensitivity analysis for rs762551.

\section{Abbreviations \\ CYP1A2: Cytochrome P450 1A2; OR: Odd ratio; Cl: Confidence interval; HAA: Heterocyclic aromatic amines, PAHs, polycyclic aromatic hydrocarbons; NNK: 4-methylnitrosamino-1- (3-pyridyl) -1-butanone; PCR-RFLP: Polymerase chain reaction-restriction fragment length polymorphism assay; SNPs: Single nucleotide polymorphisms.}

\section{Competing interests}

The authors declare that they have no competing interests.

\section{Authors' contributions}

JY designed this study. HW and ZZ drafted the manuscript. HW, YL and SH contributed to the data extraction. ZZ and FF were responsible for data analysis. All authors read and approved the final manuscript.

\section{Acknowledgements}

This work was supported by the funding of Major Program supported by Hebei Science and Technology Bureau (09276193D) and Sub-project of The National Eleventh Five-Year Scientific support Plan supported by MOST (2006BAK05B02)

\section{Author details}

'Department of Epidemiology, College of Public Health, Hebei United University, Tangshan 063000, China. ${ }^{2}$ Department of Cancer, Chemotherapy and Radiology, Tangshan Gongren Hospital, Tangshan, China. ${ }^{3}$ Department of Clinical laboratory, Tangshan Renmin Hospital, Tangshan, China.

Received: 5 April 2012 Accepted: 8 November 2012

Published: 19 November 2012

\section{References}

1. Rodriguez-Antona C, Gomez A, Karlgren M, Sim SC, Ingelman-Sundberg M: Molecular genetics and epigenetics of the cytochrome P450 gene family and its relevance for cancer risk and treatment. Hum Genet 2010, 127 (1):1-17.

2. Eaton DL, Gallagher EP, Bammler TK, Kunze KL: Role of cytochrome P4501A2 in chemical carcinogenesis: implications for human variability in expression and enzyme activity. Pharmacogenetics 1995 5(5):259-274.

3. Landi MT, Sinha R, Lang NP, Kadlubar FF: Human cytochrome P4501A2. IARC Sci Pub/ 1999, 148:173-195.

4. Jorge-Nebert LF, Jiang Z, Chakraborty R, Watson J, Jin L, McGarvey ST, Deka R, Nebert DW: Analysis of human CYP1A1 and CYP1A2 genes and their shared bidirectional promoter in eight world populations. Hum Mutat 2010, 31(1):27-40.

5. Aitchison KJ, Gonzalez FJ, Quattrochi LC, Sapone A, Zhao JH, Zaher H, Elizondo G, Bryant C, Munro J, Collier DA, et al: Identification of novel polymorphisms in the $5^{\prime}$ flanking region of CYP1A2, characterization of interethnic variability, and investigation of their functional significance. Pharmacogenetics 2000, 10(8):695-704.

6. Sterling KM Jr, Cutroneo KR: Constitutive and inducible expression of cytochromes P4501A (CYP1A1 and CYP1A2) in normal prostate and prostate cancer cells. J Cell Biochem 2004, 91(2):423-429.

7. Khvostova EP, Pustylnyak VO, Gulyaeva LF: Genetic Polymorphism of Estrogen Metabolizing Enzymes in Siberian Women with Breast Cancer. Genet Test Mol Biomarkers 2012, 16(3):167-173.

8. Singh AP, Pant MC, Ruwali M, Shah PP, Prasad R, Mathur N, Parmar D: Polymorphism in cytochrome P450 1A2 and their interaction with risk factors in determining risk of squamous cell lung carcinoma in men. Cancer Biomark 2010, 8(6):351-359.

9. B'Chir F, Pavanello S, Knani J, Boughattas S, Arnaud MJ, Saguem S: CYP1A2 genetic polymorphisms and adenocarcinoma lung cancer risk in the Tunisian population. Life Sci 2009, 84(21-22):779-784.

10. Gemignani F, Landi S, Szeszenia-Dabrowska N, Zaridze D, Lissowska J, Rudnai $P$, Fabianova $E$, Mates D, Foretova $L$, Janout $V$, et al: Development of lung cancer before the age of 50: the role of xenobiotic metabolizing genes. Carcinogenesis 2007, 28(6):1287-1293

11. Landi S, Gemignani F, Moreno V, Gioia-Patricola L, Chabrier A, Guino E, Navarro M, de Oca J, Capella G, Canzian F: A comprehensive analysis of phase I and phase II metabolism gene polymorphisms and risk of colorectal cancer. Pharmacogenet Genomics 2005, 15(8):535-546.

12. Nakajima M, Yokoi T, Mizutani M, Kinoshita M, Funayama M, Kamataki T: Genetic polymorphism in the 5'-flanking region of human CYP1A2 gene: effect on the CYP1A2 inducibility in humans. J Biochem 1999, 125(4):803-808.

13. Gunes A, Ozbey G, Vural EH, Uluoglu C, Scordo MG, Zengil H, Dahl ML: Influence of genetic polymorphisms, smoking, gender and age on CYP1A2 activity in a Turkish population. Pharmacogenomics 2009, 10 (5):769-778.

14. Ghotbi R, Christensen M, Roh HK, Ingelman-Sundberg M, Aklillu E, Bertilsson $L$ : Comparisons of CYP1A2 genetic polymorphisms, enzyme activity and the genotype-phenotype relationship in Swedes and Koreans. Eur J Clin Pharmacol 2007, 63(6):537-546.

15. Wang H, Yamamoto JF, Caberto C, Saltzman B, Decker R, Vogt TM, Yokochi L, Chanock S, Wilkens LR, Le Marchand L: Genetic variation in the bioactivation pathway for polycyclic hydrocarbons and heterocyclic amines in relation to risk of colorectal neoplasia. Carcinogenesis 2010, 32 (2):203-209.

16. Sangrajrang $S$, Sato $Y$, Sakamoto $H$, Ohnami S, Laird NM, Khuhaprema T, Brennan P, Boffetta P, Yoshida T: Genetic polymorphisms of estrogen metabolizing enzyme and breast cancer risk in Thai women. Int J Cancer 2009, 125(4):837-843.

17. Kobayashi M, Otani T, Iwasaki M, Natsukawa S, Shaura K, Koizumi Y, Kasuga Y, Sakamoto H, Yoshida T, Tsugane S: Association between dietary heterocyclic amine levels, genetic polymorphisms of NAT2, CYP1A1, and CYP1A2 and risk of stomach cancer: a hospital-based case-control study in Japan. Gastric Cancer 2009, 12(4):198-205.

18. Osawa Y, Osawa KK, Miyaishi A, Higuchi M, Tsutou A, Matsumura S, Tabuchi Y, Tsubota N, Takahashi J: NAT2 and CYP1A2 polymorphisms and lung cancer risk in relation to smoking status. Asian Pac J Cancer Prev 2007, 8 (1):103-108. 
19. DerSimonian R, Laird N: Meta-analysis in clinical trials. Control Clin Trials 1986, 7(3):177-188.

20. Schmidt FL, Oh IS, Hayes TL: Fixed-versus random-effects models in meta-analysis: model properties and an empirical comparison of differences in results. Br J Math Stat Psychol 2009, 62(Pt 1):97-128.

21. Berkey CS, Hoaglin DC, Mosteller F, Colditz GA: A random-effects regression model for meta-analysis. Stat Med 1995, 14(4):395-411.

22. Hysong SJ: Meta-analysis: audit and feedback features impact effectiveness on care quality. Med Care 2009, 47(3):356-363.

23. Biljana M, Jelena M, Branislav J, Milorad R: Bias in meta-analysis and funnel plot asymmetry. Stud Health Technol Inform 1999, 68:323-328.

24. Egger M, Davey Smith G, Schneider M, Minder C: Bias in meta-analysis detected by a simple, graphical test. BMJ 1997, 315(7109):629-634.

25. Agundez JA: Cytochrome P450 gene polymorphism and cancer. Curr Drug Metab 2004, 5(3):211-224.

26. Han XM, Zhou HH: Polymorphism of CYP450 and cancer susceptibility. Acta Pharmacol Sin 2000, 21(8):673-679.

27. Jernstrom $\mathrm{H}$, Henningson $\mathrm{M}$, Johansson $\mathrm{U}$, Olsson $\mathrm{H}$ : Coffee intake and CYP1A2*1F genotype predict breast volume in young women: implications for breast cancer. Br J Cancer 2008, 99(9):1534-1538.

28. Tsukino $\mathrm{H}$, Kuroda $\mathrm{Y}$, Nakao $\mathrm{H}$, Imai $\mathrm{H}$, Inatomi $\mathrm{H}$, Osada $\mathrm{Y}$, Katoh $\mathrm{T}$ : Cytochrome P450 (CYP) 1A2, sulfotransferase (SULT) 1A1, and Nacetyltransferase (NAT) 2 polymorphisms and susceptibility to urothelial cancer. J Cancer Res Clin Oncol 2004, 130(2):99-106.

29. Sachse C, Bhambra U, Smith G, Lightfoot TJ, Barrett JH, Scollay J, Garner RC, Boobis AR, Wolf CR, Gooderham NJ: Polymorphisms in the cytochrome P450 CYP1A2 gene (CYP1A2) in colorectal cancer patients and controls: allele frequencies, linkage disequilibrium and influence on caffeine metabolism. Br J Clin Pharmacol 2003, 55(1):68-76.

30. Kiss I, Orsos Z, Gombos K, Bogner B, Csejtei A, Tibold A, Varga Z, Pazsit E, Magda I, Zolyomi A, et al: Association between allelic polymorphisms of metabolizing enzymes (CYP 1A1, CYP 1A2, CYP 2E1, mEH) and occurrence of colorectal cancer in Hungary. Anticancer Res 2007, 27 (4C):2931-2937.

31. MARIE-GENICA Consortium on Genetic Susceptibility for Menopausal Hormone Therapy Related Breast Cancer Risk: Genetic polymorphisms in phase I and phase II enzymes and breast cancer risk associated with menopausal hormone therapy in postmenopausal women. Breast Cancer Res Treat 2010, 119(2):463-474.

32. Altayli E, Gunes S, Yilmaz AF, Goktas S, Bek Y: CYP1A2, CYP2D6, GSTM1, GSTP1, and GSTT1 gene polymorphisms in patients with bladder cancer in a Turkish population. Int Urol Nephrol 2009, 41(2):259-266.

33. Aldrich MC, Selvin S, Hansen HM, Barcellos LF, Wrensch MR, Sison JD, Kelsey KT, Buffler PA, Quesenberry CP Jr, Seldin MF, et al: CYP1A1/2 haplotypes and lung cancer and assessment of confounding by population stratification. Cancer Res 2009, 69(6):2340-2348.

34. Suzuki H, Morris JS, Li Y, Doll MA, Hein DW, Liu J, Jiao L, Hassan MM, Day RS, Bondy ML, et al: Interaction of the cytochrome P4501A2, SULT1A1 and NAT gene polymorphisms with smoking and dietary mutagen intake in modification of the risk of pancreatic cancer. Carcinogenesis 2008, 29 (6):1184-1191.

35. Saebo M, Skjelbred CF, Brekke Li K, Bowitz Lothe IM, Hagen PC, Johnsen E, Tveit KM, Kure EH: CYP1A2 164 A-->C polymorphism, cigarette smoking, consumption of well-done red meat and risk of developing colorectal adenomas and carcinomas. Anticancer Res 2008, 28(4C):2289-2295.

36. Yoshida K, Osawa K, Kasahara M, Miyaishi A, Nakanishi K, Hayamizu S, Osawa Y, Tsutou A, Tabuchi Y, Shimada E, et al: Association of CYP1A1, CYP1A2, GSTM1 and NAT2 gene polymorphisms with colorectal cancer and smoking. Asian Pac J Cancer Prev 2007, 8(3):438-444.

37. Kotsopoulos J, Ghadirian P, El-Sohemy A, Lynch HT, Snyder C, Daly M, Domchek S, Randall S, Karlan B, Zhang P, et al: The CYP1A2 genotype modifies the association between coffee consumption and breast cancer risk among BRCA1 mutation carriers. Cancer Epidemiol Biomarkers Prev 2007, 16(5):912-916.

38. Long JR, Egan KM, Dunning L, Shu XO, Cai Q, Cai H, Dai Q, Holtzman J, Gao YT, Zheng W: Population-based case-control study of AhR (aryl hydrocarbon receptor) and CYP1A2 polymorphisms and breast cancer risk. Pharmacogenet Genomics 2006, 16(4):237-243.

39. Li D, Jiao L, Li Y, Doll MA, Hein DW, Bondy ML, Evans DB, Wolff RA, Lenzi R, Pisters PW, et al: Polymorphisms of cytochrome P4501A2 and N- acetyltransferase genes, smoking, and risk of pancreatic cancer. Carcinogenesis 2006, 27(1):103-111.

40. Bae SY, Choi SK, Kim KR, Park CS, Lee SK, Roh HK, Shin DW, Pie JE, Woo ZH, Kang JH: Effects of genetic polymorphisms of MDR1, FMO3 and CYP1A2 on susceptibility to colorectal cancer in Koreans. Cancer Sci 2006, 97 (8):774-779.

41. Goodman MT, Tung KH, McDuffie K, Wilkens LR, Donlon TA: Association of caffeine intake and CYP1A2 genotype with ovarian cancer. Nutr Cancer 2003, 46(1):23-29.

42. Higgins JP, Thompson SG: Quantifying heterogeneity in a meta-analysis. Stat Med 2002, 21(11):1539-1558.

43. Smith E: Uncertainty analysis. In Encyclopedia of Environmetrics. volume 4 Edited by El-Shaarawi AH, Piegorsch WW. Chichester: Wiley; 2002:2283-2297.

44. Risch N, Merikangas K: The future of genetic studies of complex human diseases. Science 1996, 273(5281):1516-1517.

45. Lohmueller KE, Pearce CL, Pike M, Lander ES, Hirschhorn JN: Meta-analysis of genetic association studies supports a contribution of common variants to susceptibility to common disease. Nat Genet 2003, 33(2):177-182

46. Munafo MR, Flint J: Meta-analysis of genetic association studies. Trends Genet 2004, 20(9):439-444.

47. Tao L, Xiang YB, Chan KK, Wang R, Gao YT, Yu MC, Yuan JM: Cytochrome P4501A2 phenotype and bladder cancer risk: the Shanghai bladder cancer study. Int J Cancer 2011, 130(5):1174-1183.

48. Chen X, Wang L, Zhi L, Zhou G, Wang H, Zhang X, Hao B, Zhu Y, Cheng Z, He F: The G-113A polymorphism in CYP1A2 affects the caffeine metabolic ratio in a Chinese population. Clin Pharmacol Ther 2005, 78 (3):249-259.

49. Sachse C, Brockmoller J, Bauer S, Roots I: Functional significance of a C $\rightarrow>A$ polymorphism in intron 1 of the cytochrome P450 CYP1A2 gene tested with caffeine. Br J Clin Pharmacol 1999, 47(4):445-449.

50. Gilliland FD: Ethnic differences in cancer incidence: a marker for inherited susceptibility? Environ Health Perspect 1997, 105(Suppl 4):897-900.

doi:10.1186/1471-2407-12-528

Cite this article as: Wang et al: CYP1A2 rs762551 polymorphism contributes to cancer susceptibility: a meta-analysis from 19 casecontrol studies. BMC Cancer 2012 12:528.

\section{Submit your next manuscript to BioMed Central and take full advantage of:}

- Convenient online submission

- Thorough peer review

- No space constraints or color figure charges

- Immediate publication on acceptance

- Inclusion in PubMed, CAS, Scopus and Google Scholar

- Research which is freely available for redistribution 